\title{
Research Article Design of Biotin-Functionalized Luminescent Quantum Dots
}

\author{
Kimihiro Susumu, ${ }^{1}$ H. Tetsuo Uyeda, ${ }^{1,2}$ Igor L. Medintz, ${ }^{3}$ and Hedi Mattoussi ${ }^{1}$ \\ ${ }^{1}$ Division of Optical Sciences, U.S. Naval Research Laboratory, Washington, DC 20375, USA \\ ${ }^{2}$ Promega Biosciences, Inc., 277 Granada Dr., San Luis Obispo, CA 93401, USA \\ ${ }^{3}$ Center for Bio/Molecular Science and Engineering, U.S. Naval Research Laboratory, Washington, DC 20375, USA
}

Correspondence should be addressed to Hedi Mattoussi, hedimat@ccs.nrl.navy.mil

Received 25 June 2007; Accepted 21 December 2007

Recommended by Marek Osinski

\begin{abstract}
We report the design and synthesis of a tetraethylene glycol- (TEG-) based bidentate ligand functionalized with dihydrolipoic acid (DHLA) and biotin (DHLA-TEG_-biotin) to promote biocompatibility of luminescent quantum dots (QD's). This new ligand readily binds to $\mathrm{CdSe}-\mathrm{ZnS}$ core-shell QDs via surface ligand exchange. QDs capped with a mixture of DHLA and DHLA-TEGbiotin or polyethylene glycol- (PEG-) (molecular weight average 600) modified DHLA (DHLA-PEG600) and DHLA-TEGbiotin are easily dispersed in aqueous buffer solutions. In particular, homogeneous buffer solutions of QDs capped with a mixture of DHLA — PEG600 and DHLA—TEG—-biotin that are stable over broad pH range have been prepared. QDs coated with mixtures of DHLA/DHLA - TEG — biotin and with DHLA_PEG600/DHLA-TEG_-biotin were tested in surface binding assays and the results indicate that biotin groups on the QD surface interact specifically with NeutrAvidin-functionalized microtiter well plates.
\end{abstract}

Copyright ( $) 2007$ Kimihiro Susumu et al. This is an open access article distributed under the Creative Commons Attribution License, which permits unrestricted use, distribution, and reproduction in any medium, provided the original work is properly cited.

\section{INTRODUCTION}

Luminescent semiconductor nanocrystals, such as those made of CdSe-ZnS core-shell quantum dots (QD's), provide substantial advantages for use as stable fluorophores in biological assays and imaging. As synthesized by conventional methods using high-temperature solution reaction from organometallic precursors, highly luminescent QD's are capped with hydrophobic organic ligands primarily made of a mixture of trioctylphosphine/trioctylphosphine oxide (TOP/TOPO). Further surface modification is required to make them water-soluble and biocompatible. Methods reported to date for achieving water solubility of such materials include silica coating [1], encapsulation of the native TOP/TOPO-capped QD's within amphiphilic polymer shells [2] or lipid micelles [3], and cap exchange of the native TOP/TOPO caps with hydrophilic ligands [4-6]. The strategy based on cap exchange with bifunctional ligands is relatively simple to implement and has the potential to provide compact hydrophilic QD's, a desired property in targeted studies, including fluorescence resonance energy transfer(FRET-) based sensing and cellular uptake [7-11].
We have previously utilized readily available thioctic acid and polyethylene glycols (PEGs) in simple esterification schemes, followed by reduction of the 1,2-dithiolane to synthesize a series of PEG-terminated dihydrolipoic acid (DHLA-PEG) capping substrates [12]. The cap exchange reaction of TOP/TOPO-capped QD's with these substrates produced water-soluble nanocrystals that are stable over extended periods of time and over a relatively broad $\mathrm{pH}$ range, from weakly acidic to basic conditions ( $\mathrm{pH}$ 5 12). Though compact and stable, those ligands lack specific functional end groups and do not allow easy implementation of simple conjugation techniques, such as avidin-biotin binding.

In this study, we further expanded those findings and report the design and synthesis of ligands functionalized with a biotin end group. The designed ligands have a central tetraethylene glycol (TEG) segment, a dithiol terminal group for anchoring on the QD surface and a lateral biotin. Appending biotin at the end of surface-attached ligands should permit the use of the ubiquitous avidin-biotin binding motif to conjugate QD's to proteins and other biomolecules via an avidin bridge. Cap exchange reactions were carried out with mixed ligands and preliminary binding assays of the 
biotin-coated water-soluble QD's to NeutrAvidin-functionalized substrates showed that specific capture of the QD's due to avidin-biotin interactions was achieved.

\section{EXPERIMENTAL SECTION}

All manipulations were carried out under dry nitrogen and air-sensitive solids were handled in an MBraun Labmaster 130 glovebox. TEG was purchased from Sigma-Aldrich (Milwaukee, Wis, USA). Triphenylphosphine, thioctic acid, 4-(N,N-dimethylamino)pyridine, $N, N^{\prime}$-dicyclohexylcarbodiimide, and $N$-hydroxysuccinimide were purchased from Acros Organics (Morris Plains, NJ, USA). Sodium azide and biotin were purchased from Alfa Aesar (Ward Hill, Mass, USA). Methanesulfonyl chloride was purchased from GFS Chemicals (Powell, Ohio, USA). Sodium borohydride was purchased from Strem Chemicals (Newburyport, Mass, USA). All the other chemicals (including solvents) were purchased from Sigma-Aldrich and Acros Organics. Tetrahydrofuran (THF) was dried over $\mathrm{CaH}_{2}$ before use. Deuterated solvents employed in all NMR measurements were used as received. Chemical shifts for ${ }^{1} \mathrm{H}$ NMR spectra are reported relative to tetramethylsilane (TMS) signal in the deuterated solvent (TMS, $\delta=0.00 \mathrm{ppm}$ ). All $J$ values are reported in Hertz. Column chromatography was performed on bench top, using silica gel (Bodman Industries, Aston, Pa, USA, $60 \AA, 230-400$ mesh).

${ }^{1} \mathrm{H}$ NMR spectra were recorded on a Bruker SpectroSpin $400 \mathrm{MHz}$ spectrometer. Electronic absorption spectra were recorded using an HP 8453 diode array spectrophotometer (Agilent technologies, Santa Clara, Calif, USA), while fluorescence spectra were collected using a Spex Fluorolog3 spectrophotometer (Jobin Yvon Inc, Edison, NJ, USA). To account for the nonlinear (wavelength-dependent) quantum efficiency of the PMT detector, the fluorescence spectra were corrected using calibration curves accounting for the wavelength-dependence of the PMT's detection efficiency.

\subsection{Ligand synthesis}

The biotin-terminated ligands were synthesized stepwise using commercially available TEG. The choice of a short TEG segment to test this synthetic scheme was motivated by the well-defined chain length of the TEG molecules compared to longer PEG chains, which is expected to make separation using column chromatography easier. In the following section we detail the synthesis of each intermediate compound necessary for preparation of the final DHLA-TEG-biotin ligand. All the compounds were characterized by thin layer chromatography (TLC) and ${ }^{1} \mathrm{H}$ NMR.

\subsubsection{1,11-Diazido-3,6,9-trioxaundecane}

Diazide-functionalization of TEG (3): compound 3 was prepared following published procedures [13]. TEG (40.0 g, $206 \mathrm{mmol})$, tetrahydrofuran (THF) $(350 \mathrm{~mL})$, and methanesulfonyl chloride $(53.0 \mathrm{~g}, 463 \mathrm{mmol})$ were mixed in a $1 \mathrm{~L}$ round bottom flask and cooled to $0^{\circ} \mathrm{C}$. A solution of triethylamine ( $49.0 \mathrm{~g}, 484 \mathrm{mmol})$ in THF $(50 \mathrm{~mL})$ was added drop- wise over 30 minutes and the mixture was stirred at room temperature over 20 hours. The reaction was then diluted with water $(200 \mathrm{~mL})$ and $\mathrm{NaHCO}_{3}(12.5 \mathrm{~g})$. Sodium azide ( $36.0 \mathrm{~g}, 554 \mathrm{mmol}$ ) was added and the biphasic reaction mixture was first heated to $65^{\circ} \mathrm{C}$ to distill off the THF, and then to $70^{\circ} \mathrm{C}$ for 14 hours. The reaction mixture was cooled to room temperature and extracted with ether $(3 \times 75 \mathrm{~mL})$. The combined organic extracts were dried over $\mathrm{MgSO}_{4}$, filtered, and evaporated to give brownish oil. The product was purified by flash column chromatography (hexane : EtOAc $1: 1$ ) and the solvent evaporated to give $39 \mathrm{~g}$ (a yield of 78\%) as a colorless oil. ${ }^{1} \mathrm{H} \mathrm{NMR}\left(400 \mathrm{MHz}, \mathrm{CDCl}_{3}\right): \delta(\mathrm{ppm}) 3.66-3.71(\mathrm{~m}$, $\left.12 \mathrm{H},-\mathrm{OCH}_{2} \mathrm{CH}_{2}-\right), 3.40\left(\mathrm{t}, 4 \mathrm{H}, J=5.1 \mathrm{~Hz},-\mathrm{CH}_{2} \mathrm{~N}_{3}\right)$.

\subsubsection{1-Amino-11-azido-3,6,9-trioxaundecane}

Transformation to monoamine-terminated TEG (4) [13]: 1,11-Diazido-3,6,9-trioxaundecane (3) (33.0 g, $135 \mathrm{mmol})$ and $250 \mathrm{~mL}$ of $0.7 \mathrm{M} \mathrm{H}_{3} \mathrm{PO}_{4}$ were placed in a $1 \mathrm{~L}$ round bottom flask and cooled to $0^{\circ} \mathrm{C}$ using an ice bath while stirring. A solution of triphenylphosphine $\left(\mathrm{PPh}_{3}\right)(29.0 \mathrm{~g}, 110 \mathrm{mmol})$ in ether $(250 \mathrm{~mL})$ was slowly added via cannula and the temperature of the reaction was maintained below $5^{\circ} \mathrm{C}$. Once addition was complete, the reaction mixture was warmed to room temperature and stirred under nitrogen for an additional 16 hours. The biphasic solution was separated and the aqueous layer was washed with ether $(3 \times 100 \mathrm{~mL})$. Potassium hydroxide $(\mathrm{KOH})$ ( $30 \mathrm{~g}$ ) was slowly added to the aqueous layer and cooled to $0^{\circ} \mathrm{C}$ overnight. The solution was filtered and the filtrate was basified with an additional $40 \mathrm{~g}$ of $\mathrm{KOH}$ and cooled to room temperature. The reaction mixture was extracted with $\mathrm{CHCl}_{3}(4 \times 75 \mathrm{~mL})$ and the combined organic extracts were dried over $\mathrm{MgSO}_{4}$, filtered, and the solvent was evaporated to give $18.5 \mathrm{~g}$ of an oil with a slight yellow color. The monoamine transformation reaction has a yield of $63 \% .{ }^{1} \mathrm{H} \mathrm{NMR}\left(400 \mathrm{MHz}, \mathrm{CDCl}_{3}\right): \delta(\mathrm{ppm}) 3.57(\mathrm{~m}$, $\left.10 \mathrm{H},-\mathrm{OCH}_{2} \mathrm{CH}_{2}-\right), 3.40\left(\mathrm{t}, 2 \mathrm{H}, \mathrm{J}=5.2 \mathrm{~Hz},-\mathrm{CH}_{2} \mathrm{CH}_{2} \mathrm{NH}_{2}\right.$ ), $3.29\left(\mathrm{t}, 2 \mathrm{H}, \mathrm{J}=5.0 \mathrm{~Hz},-\mathrm{CH}_{2} \mathrm{~N}_{3}\right), 2.75(\mathrm{t}, 2 \mathrm{H}, \mathrm{J}=5.2 \mathrm{~Hz},-$ $\mathrm{CH}_{2} \mathrm{CH}_{2} \mathrm{NH}_{2}$ ).

\subsubsection{5-([1,2]Dithiolan-3-yl)pentanoic acid- $N$ - $\left(3^{\prime}, 6^{\prime}, 9^{\prime}\right.$-trioxaundecane-11' -azido)amide}

Coupling of amino-terminated TEG to thioctic acid: TA-TEG-N 3 , compound 5: thioctic acid (11.1 g, 53.8 mmol), 1-amino-11-azido-3,6,9-trioxaundecane (4) (11.2 g, $51.3 \mathrm{mmol})$, 4-dimethylaminopyridine $(1.26 \mathrm{~g}, 10.3 \mathrm{mmol})$, and $\mathrm{CH}_{2} \mathrm{Cl}_{2}(200 \mathrm{~mL})$ were placed in a $500 \mathrm{~mL}$ round bottom flask, cooled to $0^{\circ} \mathrm{C}$ and stirred under $\mathrm{N}_{2}$ atmosphere. $N, N^{\prime}$-Dicyclohexylcarbodiimide (DCC) (11.1 g, $53.8 \mathrm{mmol}$ ) was slowly added and reaction mixture was stirred at $0^{\circ} \mathrm{C}$ for 2 hours, then warmed to room temperature and stirred for an additional 16 hours. The reaction mixture was filtered over a plug of celite and rinsed with EtOAc. The filtrate was evaporated and the crude material was purified by flash column chromatography $\left(\mathrm{CHCl}_{3}: \mathrm{MeOH} 97: 3\right.$ as the eluent) to give $11.7 \mathrm{~g}$ (yield of $56 \%$ ) of a yellow oil. ${ }^{1} \mathrm{H}$ NMR $(400 \mathrm{MHz}$, $\left.\mathrm{CDCl}_{3}\right): \delta(\mathrm{ppm}) 6.15(\mathrm{~m}, 1 \mathrm{H}, \mathrm{CO}-\mathrm{NH}), 3.50-3.62(\mathrm{~m}, 11 \mathrm{H}$, 
$-\mathrm{OCH}_{2} \mathrm{CH}_{2}-$ and $\left.\mathrm{CH}\right), 3.47(\mathrm{t}, 2 \mathrm{H}, \mathrm{J}=5.0 \mathrm{~Hz}, \mathrm{CO}-\mathrm{NH}-$ $\mathrm{CH}_{2} \mathrm{CH}_{2} \mathrm{O}-$ ) $, 3.36\left(\mathrm{t}, 2 \mathrm{H}, \mathrm{J}=5.5 \mathrm{~Hz}, \mathrm{CO}-\mathrm{NH}-\mathrm{CH}_{2}-\right), 3.31$ $\left(\mathrm{t}, 2 \mathrm{H}, \mathrm{J}=5.0 \mathrm{~Hz},-\mathrm{CH}_{2} \mathrm{~N}_{3}\right), 2.98-3.13\left(\mathrm{~m}, 2 \mathrm{H}, \mathrm{CH}_{2}\right), 2.32-$ $2.42(\mathrm{~m}, 1 \mathrm{H}, \mathrm{CH}), 2.10\left(\mathrm{t}, 2 \mathrm{H}, \mathrm{J}=7.4 \mathrm{~Hz},-\mathrm{CH}_{2}-\mathrm{CO}-\mathrm{NH}-\right)$, 1.77-1.87 (m, 1H, CH), 1.50-1.68 (m, 4H, $\left.\mathrm{CH}_{2}\right), 1.30-1.45$ $\left(\mathrm{m}, 2 \mathrm{H}, \mathrm{CH}_{2}\right)$.

\subsubsection{5-([1,2]Dithiolan-3-yl)pentanoic acid-N-(3'6' 9' $^{\prime}$-trioxaundecane-11-amino)amide}

Transformation to amine-terminated TA-TEG, compound 6: compound $5(11.0 \mathrm{~g}, 27 \mathrm{mmol})$ was dissolved in THF $(150 \mathrm{~mL})$ in a $300 \mathrm{~mL}$ round bottom flask fitted with a condenser and nitrogen inlet. $\mathrm{PPh}_{3}(15.0 \mathrm{~g}, 81 \mathrm{mmol})$ was added and the reaction was heated to reflux for 20 hours. The reaction mixture was cooled to room temperature and diluted with $15 \mathrm{~mL}$ of water and stirred for an additional 20 hours. The solvent was evaporated and the crude product was purified by flash column chromatography. Unreacted $\mathrm{PPh}_{3}$ and triphenylphosphine oxide were removed with $\mathrm{CHCl}_{3}$ and the eluent was switched to $\mathrm{CHCl}_{3}: \mathrm{MeOH}: \mathrm{Et}_{3} \mathrm{~N}(45: 45: 10)$ to collect the desired product. Removal of the solvent gave $9.0 \mathrm{~g}$ (yield of $88 \%$ ) of gelatinous yellow oil. ${ }^{1} \mathrm{H}$ NMR $(400 \mathrm{MHz}$, methanol- $\left.\mathrm{d}_{4}\right): \delta$ (ppm) 3.41-3.59 (m, 12H, $\left.-\mathrm{OCH}_{2} \mathrm{CH}_{2}-\right)$, $3.26\left(\mathrm{t}, 2 \mathrm{H}, J=5.1 \mathrm{~Hz},-\mathrm{CO}-\mathrm{NH}-\mathrm{CH}_{2}-\right)$, 3.22 (m, 1H, CH-), 2.97-3.12(m, 2H, CH$), 2.71\left(\mathrm{t}, 2 \mathrm{H}, \mathrm{J}=5.3 \mathrm{~Hz},-\mathrm{CH}_{2} \mathrm{CH}_{2}-\right.$ $\left.\mathrm{NH}_{2}\right), 2.32-2.42(\mathrm{~m}, 1 \mathrm{H}, \mathrm{CH}), 2.12\left(\mathrm{t}, 2 \mathrm{H}, \mathrm{J}=7.4 \mathrm{~Hz},-\mathrm{CH}_{2}-\right.$ CO-NH-), 1.75-1.85 (m, 1H, CH), $1.47-1.69\left(\mathrm{~m}, 4 \mathrm{H}, \mathrm{CH}_{2}\right)$, 1.29-1.44 (m, 2H, $\left.\mathrm{CH}_{2}\right)$.

\subsubsection{TA-TEG-Biotin (7)}

Biotinyl-N-hydroxysuccinimide was first prepared following the synthetic procedure previously reported [14-16]. Compound 6 (2.3 g, $6.0 \mathrm{mmol})$, biotinyl- $N$-hydroxysuccinimide $(2.05 \mathrm{~g}, 6.0 \mathrm{mmol})$ were dissolved in DMF $(50 \mathrm{~mL})$ and stirred at room temperature under $\mathrm{N}_{2}$ atmosphere. $\mathrm{Et}_{3} \mathrm{~N}$ (3.0 g, $30 \mathrm{mmol}$ ) was added dropwise via syringe and the reaction was stirred for 16 hours. The solvent was evaporated under reduced pressure and the yellow residue was purified by flash column chromatography (using $\mathrm{CHCl}_{3}: \mathrm{MeOH}$ $95: 5$ as the eluent). The solvent was evaporated to give $3.1 \mathrm{~g}$ (a yield of $85 \%$ ) of viscous yellow oil. ${ }^{1} \mathrm{H}$ NMR $(400 \mathrm{MHz}$, $\left.\mathrm{CDCl}_{3}\right): \delta(\mathrm{ppm}) 6.79(\mathrm{~m}, 1 \mathrm{H}, \mathrm{CO}-\mathrm{NH}), 6.59(\mathrm{~m}, 1 \mathrm{H}, \mathrm{CO}-$ $\mathrm{NH}), 6.49$ (s, 1H, biotin CO-NH), 6.02 (s, 1H, biotin CO$\mathrm{NH}), 4.41(\mathrm{~m}, 1 \mathrm{H}$, biotin $\mathrm{CO}-\mathrm{NH}-\mathrm{CH}), 4.22(\mathrm{~m}, 1 \mathrm{H}$, biotin $\mathrm{CO}-\mathrm{NH}-\mathrm{CH}), 3.52\left(\mathrm{~m}, 9 \mathrm{H},-\mathrm{OCH}_{2} \mathrm{CH}_{2}-\right.$ and $\left.\mathrm{CH}\right)$, 3.45 ( $\mathrm{m}, 4 \mathrm{H}, \mathrm{CO}-\mathrm{NH}-\mathrm{CH}_{2} \mathrm{CH}_{2} \mathrm{O}-$ ), 3.30 (m, 4H, CO-NH$\left.\mathrm{CH}_{2}\right), 2.96-3.10\left(\mathrm{~m}, 3 \mathrm{H}, \mathrm{CH}_{2}\right.$ and $\left.\mathrm{CH}-\mathrm{S}\right), 2.76-2.83(\mathrm{~m}, 1 \mathrm{H}$, $\mathrm{CH}-\mathrm{S}), 2.65$ (d, $1 \mathrm{H}, J=12.8 \mathrm{~Hz}, \mathrm{CH}-\mathrm{S}), 2.30-2.40(\mathrm{~m}, 1 \mathrm{H}$, $\mathrm{CH}), 2.11\left(\mathrm{~m}, 4 \mathrm{H}, \mathrm{NH}-\mathrm{CO}-\mathrm{CH}_{2}\right), 1.75-1.85(\mathrm{~m}, 1 \mathrm{H}, \mathrm{CH})$, 1.45-1.68 (m, 8H, CH $\mathrm{CH}_{2}, 1.26-1.42\left(\mathrm{~m}, 4 \mathrm{H}, \mathrm{CH}_{2}\right)$.

\subsubsection{DHLA-TEG-biotin (8)}

Compound 7 ( $2.0 \mathrm{~g}, 3.3 \mathrm{mmol})$ was dispersed in a mixture of ethanol $(40 \mathrm{~mL})$ and water $(20 \mathrm{~mL})$ while stirring in a $125 \mathrm{~mL}$ flask. $\mathrm{NaBH}_{4}(700 \mathrm{mg}, 18.5 \mathrm{mmol})$ was slowly added and the solution was stirred at room temperature for 4 hours. The reaction mixture was diluted with water $(200 \mathrm{ml})$ and extracted with $\mathrm{CHCl}_{3}(4 \times 50 \mathrm{ml})$, dried over $\mathrm{MgSO}_{4}$, filtered, and the solvent was evaporated. The crude product was purified by flash column chromatography $\left(\mathrm{CHCl}_{3}: \mathrm{MeOH} 95: 5\right.$ as the eluent) to give $1.53 \mathrm{~g}$ (a yield of $77 \%$ ) of colorless viscous oil. ${ }^{1} \mathrm{H}$ NMR $\left(400 \mathrm{MHz}, \mathrm{CDCl}_{3}\right): \delta(\mathrm{ppm}) 6.96(\mathrm{~m}, 1 \mathrm{H}$, $\mathrm{CO}-\mathrm{NH}), 6.69(\mathrm{~m}, 1 \mathrm{H}, \mathrm{CO}-\mathrm{NH}), 6.63(\mathrm{~s}, 1 \mathrm{H}$, biotin CO$\mathrm{NH}), 6.03$ ( $\mathrm{s}, 1 \mathrm{H}$, biotin CO-NH), 4.37 ( $\mathrm{m}, 1 \mathrm{H}$, biotin CO$\mathrm{NH}-\mathrm{CH}), 4.18(\mathrm{~m}, 1 \mathrm{H}$, biotin $\mathrm{CO}-\mathrm{NH}-\mathrm{CH}), 3.50(\mathrm{~m}, 8 \mathrm{H},-$ $\left.\mathrm{OCH}_{2} \mathrm{CH}_{2}-\right)$, $3.42\left(\mathrm{~m}, 4 \mathrm{H}, \mathrm{CO}-\mathrm{NH}-\mathrm{CH}_{2} \mathrm{CH}_{2} \mathrm{O}-\right)$, 3.29 (m, $\left.4 \mathrm{H}, \mathrm{CO}-\mathrm{NH}-\mathrm{CH}_{2}\right), 2.96-3.06(\mathrm{~m}, 1 \mathrm{H}, \mathrm{CH}-\mathrm{S}), 2.70-2.84$ ( $\mathrm{m}, 2 \mathrm{H}, \mathrm{CH}-\mathrm{S}$ and $\mathrm{CH}-\mathrm{SH}), 2.46-2.66(\mathrm{~m}, 3 \mathrm{H}, \mathrm{CH}-\mathrm{S}$ and $\left.\mathrm{CH}_{2}-\mathrm{SH}\right), 2.07$ (m, 4H, NH-CO-CH $), 1.71-1.83(\mathrm{~m}, 1 \mathrm{H}$, $\mathrm{CH}), 1.35-1.67\left(\mathrm{~m}, 13 \mathrm{H}, \mathrm{CH}_{2}\right), 1.28\left(\mathrm{t}, 1 \mathrm{H}, J=8.0 \mathrm{~Hz}, \mathrm{CH}_{2}-\right.$ $\mathrm{SH}), 1.23(\mathrm{~d}, 1 \mathrm{H}, J=7.6 \mathrm{~Hz}, \mathrm{CH}-\mathrm{SH})$.

\subsection{Quantum dot synthesis and cap exchange}

The CdSe-ZnS core-shell QD's used were synthesized using high-temperature reaction of organometallic precursors in a mixture of TOP/TOPO and alkylamine, as described in the literature [17-20]. Cap exchange of the TOP/TOPO-capped QD's with the newly synthesized ligands to achieve water solubility (a mixture of $\mathbf{1}$ and $\mathbf{8}$, and a mixture of $\mathbf{2}$ and $\mathbf{8}$ ) was carried out following procedures described previously $[5,12,21]$. For cap exchange with a mixture of 2 and $8, \sim 50-$ $300 \mathrm{mg}$ of TOP/TOPO-capped QD's were precipitated using $\mathrm{EtOH}$ and the supernatant was discarded. To the precipitate $\sim 0.5 \mathrm{~mL}$ in total of pure or mixed ligands and $\sim 0.5 \mathrm{~mL}$ of EtOH were added. The mixture was then heated to $60 \sim 80^{\circ} \mathrm{C}$ while stirring for a period of 6 to 12 hours. Once homogenized, the sample was then precipitated out with mixtures of hexane, $\mathrm{EtOH}$, and $\mathrm{CHCl}_{3}$ (approximate ratio is $11: 10: 1$, this ratio may vary from batch to batch); the precipitate was dispersed in water. The homogenized solution was further purified using $3 \sim 4$ cycles of concentration/dilution with an ultrafree centrifugal filtration device (Millipore, $M_{w}$ cutoff $\sim 50,000 \mathrm{Da})$ to remove excess ligands and other materials from the solution. Cap exchange with a mixture of $\mathbf{1}$ and $\mathbf{8}$ was done similarly though some modifications are required for purification steps. [21] DMF $(\sim 5 \mathrm{~mL})$ was added to the reaction mixture after the solution was homogenized. The QD's were precipitated out by adding excess potassium tertbutoxide. The mixture was centrifuged and the supernatant was discarded. The precipitate was dispersed in water and the homogenized solution was further purified as described above.

\subsection{Gel electrophoresis}

Samples were separated in agarose gels as described previously [22]. Briefly, samples were mixed with 30\% glycerol, loaded into $1.5 \%$ agarose gels buffered with $1 \mathrm{X}$ Tris borate EDTA (TBE) in TBE running buffer $(\mathrm{pH} \sim 8.3)$ and run at 10 volts/cm for $\sim 1$ hour at ambient temperature. The gelshift bands were visualized using the QD photoluminescence collected on a Kodak 440 Digital Image Station (Rochester, NY, USA) equipped with a long-pass cutoff filter; samples were illuminated with UV light (365 nm excitation). 


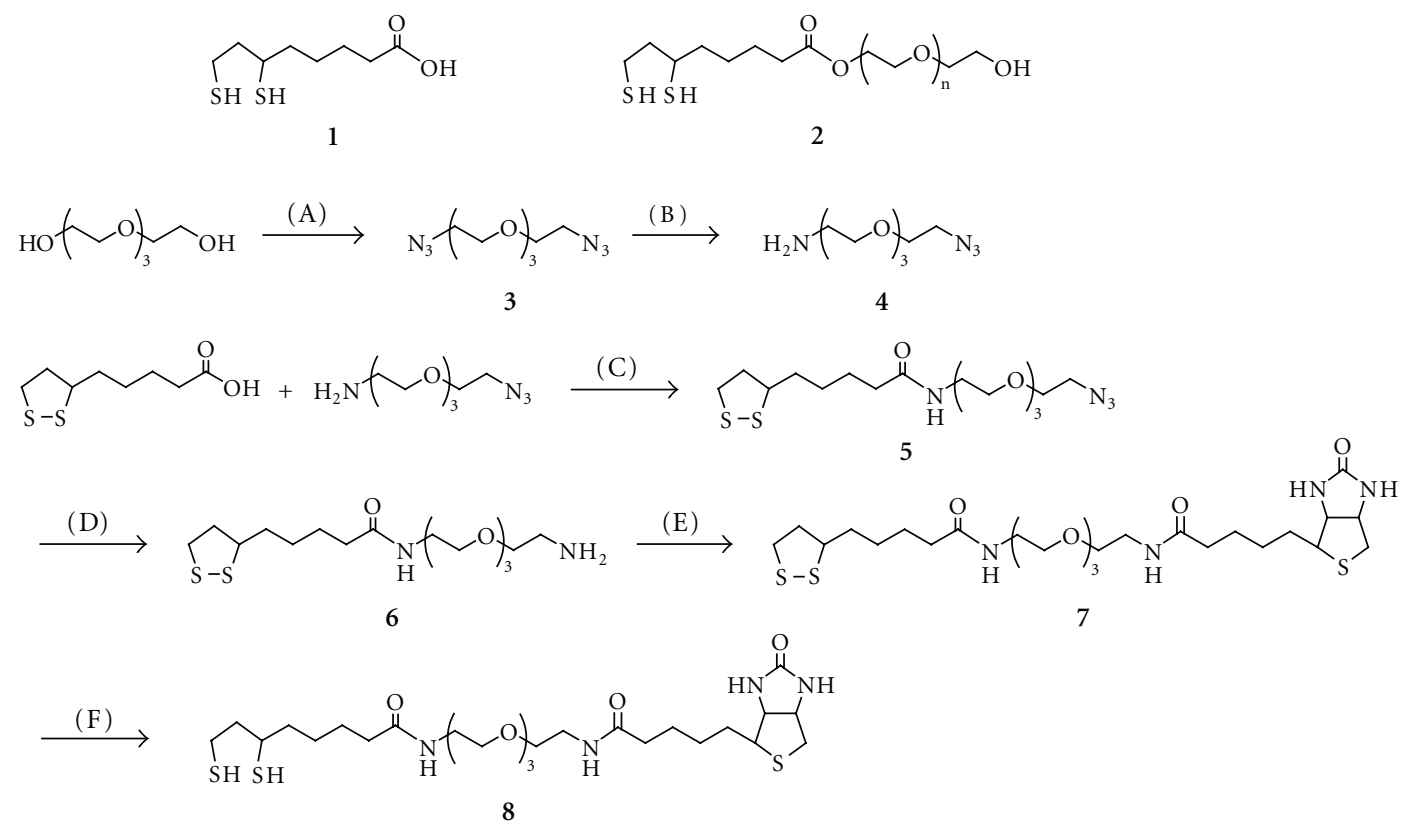

FIGURE 1: Chemical structures and synthetic routes of the surface ligands used in this study: (A) (i) $\mathrm{MsCl}_{2} \mathrm{Et}_{3} \mathrm{~N}, \mathrm{THF}, 0^{\circ} \mathrm{C} \rightarrow 20^{\circ} \mathrm{C}, 20$ hours; (ii) $\mathrm{NaN}_{3}, \mathrm{NaHCO}_{3}, \mathrm{H}_{2} \mathrm{O}, 70^{\circ} \mathrm{C}, 14$ hours; (B) $\mathrm{PPh}_{3}, 0.7 \mathrm{M} \mathrm{H}_{3} \mathrm{PO}_{4}, \mathrm{Et}_{2} \mathrm{O},<5^{\circ} \rightarrow$ room temperature, 16 hours; (C) DCC, $\mathrm{DMAP}^{\circ} \mathrm{CH}_{2} \mathrm{Cl}_{2}, 0^{\circ} \mathrm{C}$, 2 hour $\rightarrow$ room temperature, 20 hours; (D) $\mathrm{PPh}_{3}, \mathrm{H}_{2} \mathrm{O}$, THF, reflux, 20 hour $\rightarrow$ room temperature, 20 hours; (E) Biotin $N$-hydroxysuccinimide ester, $\mathrm{Et}_{3} \mathrm{~N}$, DMF, room temperature, 16 hours; (F) $\mathrm{NaBH}_{4}, \mathrm{EtOH}, \mathrm{H}_{2} \mathrm{O}$, room temperature, 4 hours.

\subsection{Surface binding assay}

The binding capacity of NeutrAvidin-covered 96-well microtiter flat-bottom plates from Pierce Biotechnology is 60 picomoles of biotin per well. $100 \mu \mathrm{L}$ aliquots of QD samples (with the desired cap mixture at $\sim 7 \mathrm{pM}$ concentration) were added to the wells and let incubate overnight at room temperature. The fluorescence intensity was measured using a Tecan Safire Dual Monochromator Multifunction Microtiter Plate Reader (Tecan, Research Triangle Park, NC, USA), then plates were washed 3 times with $10 \mathrm{mM} \mathrm{Na}$ tetraborate buffer ( $\mathrm{pH}$ 9) supplemented with $0.02 \%$ Tween and the fluorescence signal was measured again; $300 \mathrm{~nm}$ excitation line was used for all the samples. The remaining fluorescence intensities were calculated as approximate binding percentages. Those values were normalized by setting the highest binding percentage to $100 \%$.

\section{RESULTS AND DISCUSSION}

The chemical structures and synthetic schemes of a few representative ligands (namely DHLA, DHLA-PEG600, and DHLA-TEG-biotin) and reaction steps involved are summarized in Figure 1. TEG was first transformed into diazideterminated-TEG (3) using a two-step reaction with methanesulfonyl chloride and sodium azide. Monosubstitution of one azide into an amine group was carried out in biphasic acidic solution to improve the efficiency of selective formation of the monsubstituted product (4) [13]. Thioctic acid (TA) and $\mathrm{N}_{3}-\mathrm{TEG}-\mathrm{NH}_{2}$ (4) were coupled with
$N, N^{\prime}$-dicyclohexylcarbodiimide (DCC) to provide azideterminated compound 5. The terminal azido group of $\mathbf{5}$ was reduced with $\mathrm{PPh}_{3}$ and $\mathrm{H}_{2} \mathrm{O}$ to obtain an amine-terminated TA-TEG ligand (Compound 6). Biotin-functionalized compound 7 was synthesized by coupling between 6 and Biotin $N$-hydroxysuccinimide ester. Finally, the terminal 1,2dithiolane group in compound 7 was reduced with $\mathrm{NaBH}_{4}$ to obtain DHLA terminal group as a bidentate thiol anchoring unit.

We verified quality of the new compounds by collecting ${ }^{1} \mathrm{H}-\mathrm{NMR}$ spectra throughout the various steps employed. The ${ }^{1} \mathrm{H}$-NMR spectra show that TEG-modified compounds have large peaks around $\sim 3.6 \mathrm{ppm}$, which are ascribed to $\mathrm{CH}_{2}$ groups of TEG chains. After coupling between 6 and biotin $N$-hydroxysuccinimide ester, new distinct multiplet peaks $(2.6 \sim 2.9,4.22$, and $4.41 \mathrm{ppm})$ are measured in the NMR spectra, which were ascribed to biotin-ring protons. In addition, following reduction of the 1,2-dithiolane group with $\mathrm{NaBH}_{4}$, new doublet and triplet peaks appeared at 1.23 and $1.28 \mathrm{ppm}$, respectively. These two peaks were assigned as thiol protons of DHLA unit (open dithiol) [12]. The observed changes in each collected spectrum indicate that each reaction step produced the desired compound.

We have previously shown that QD's capped with DHLA-PEG600 or DHLA-PEG1000 ligands can be dispersed in buffers with $\mathrm{pH}$ ranging between $5 \sim 12$ [12]. However, cap exchange of TOP/TOPO with DHLA-TEG-biotin alone did not produce water-soluble QD's, a property attributable to the rather short TEG segment combined with the hydrophobic nature of the biotin group [12]. To achieve 


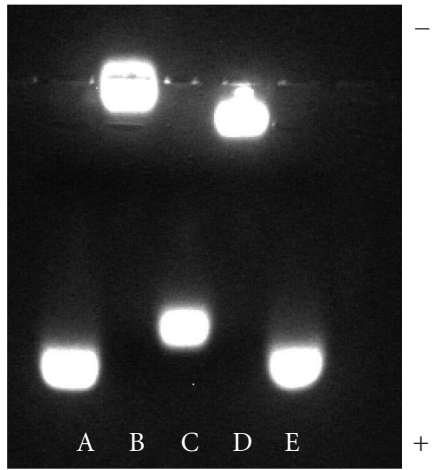

Figure 2: Gel shift of 510-nm emitting CdSe-ZnS QD's coated with different ligands in 1.5\% agarose gel buffered with TBE buffer: (A,E) DHLA; (B) DHLA-PEG600; (C) DHLA : DHLA-TEG-Biotin (7:1); (D) DHLA-PEG600: DHLA-TEG-Biotin (7:1).

water solubility using the new DHLA-TEG-biotin ligands (compound 8), TOP/TOPO-capped QD's were instead dispersed (during cap exchange) with mixtures of ligand $\mathbf{8}$ and either DHLA (1) or DHLA-PEG600 (2). Rather low to modest DHLA-TEG-biotin ratios (5-25\%) were used in the mixtures for cap exchange. In addition to promoting easy transfer into buffer solutions, this approach ensures that only controlled and low density of biotin groups are available on each QD. This should also allow control over the number of biological receptors coupled to a single QD and potentially biological activity of the QD-bioconjugates. In this particular study, we used a mixture of compound $\mathbf{1}$ and compound $\mathbf{8}$ (at 7:1 molar ratio), and a mixture of compound 2 and compound 8 (at 7:1 molar ratio) for the cap exchange.

In the first characterization experiment of the cap exchange, we monitored changes in the electrophoretic mobility of QD's (run on a 1.5\% agarose gel) as a function of the capping mixture used. The gel image in Figure 2 shows a side-by-side comparison of the mobility shift of $510 \mathrm{~nm}$ emitting QD cap exchanged with either a mixture of DHLA:DHLA-TEG-biotin (7:1) (lane C) or a mixture of DHLA-PEG600: DHLA-TEG-biotin (7:1) (lane D), together with control samples made of either QD's capped with DHLA (lanes A and E) or QD's capped with DHLAPEG600 (lane B). The data clearly show that on the one hand QD's capped with only DHLA experienced the highest mobility shift (towards the positive electrode) in this series; this result is attributed to the presence of carboxyl groups on DHLA molecules, which can be deprotonated and negatively charged in basic buffer solutions. On the other hand, DHLA-PEG600-capped QD's showed no mobility shift under applied voltage (materials did not migrate from the loading well), indicating that these QD's are essentially neutral; water solubility for this sample is mainly promoted by hydrophilicity of the long PEG chains. In comparison, the gel shift of the QD with DHLA: DHLA-TEG-Biotin (7:1) was slightly lower than that of the DHLA-capped QD's, whereas QD's capped with DHLA-PEG600:DHLA-TEGBiotin $(7: 1)$ mixture showed a very small shift compared with DHLA-PEG600-capped QD's. For QD's capped with

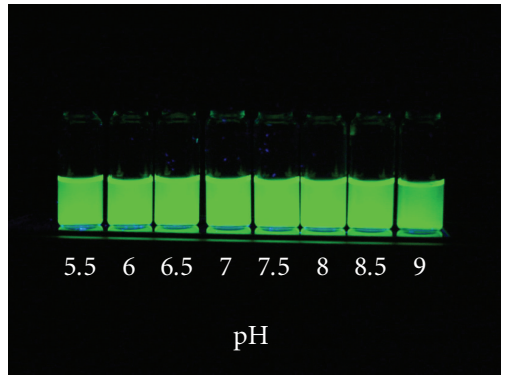

FIgure 3: Luminescence image set of $540 \mathrm{~nm}$ emitting CdSe-ZnS QD with DHLA-PEG600: DHLA-TEG-Biotin (4:1) at pH $5.5 \sim 9$ in phosphate buffer saline at various $\mathrm{pH}$ values at room temperature. Samples were excited with a handheld UV lamp at $365 \mathrm{~nm}$.

DHLA: DHLA-TEG-Biotin $(7: 1)$ mixture, partial occupation of the nanocrystal surface by DHLA-TEG-Biotin (compared with DHLA-capped QD's) has led to reduced number of charges per QD and thus small reduction in the gel mobility shift (lane C). The nonzero mobility shift (even though extremely small) measured for QD's capped with a mixture of DHLA-PEG600 : DHLA-TEG-Biotin may be due to a slight/partial charging of biotin or amide groups on the chain under applied voltage. Overall, the present gel electrophoresis data confirm that cap exchange of TOP/TOPOcapped QD's with a ligand mixture produced nanocrystals that have both types of capping ligands; furthermore, the overall relative proportions of each ligand used during cap exchange is preserved in the final QD samples.

Absorption and fluorescence spectra were measured for both the native TOP/TOPO-capped QD's in toluene and the new hydrophilic QD's capped with DHLA-TEG derivatives in $\mathrm{H}_{2} \mathrm{O}$ (data not shown). Absorption spectra measured before and after the cap exchange were essentially unchanged, though a few $\mathrm{nm}$ red shift of the lowest absorption maximum of the hydrophilic QD's was occasionally measured compared with that of QD's capped with TOP/TOPO ligands. The fluorescence spectra showed similar trends. These occasional small changes in the optical properties of QD's following transfer into aqueous solutions are commonly observed $[1,12,23]$. The fluorescence quantum yields of the waterdispersed QD's change from batch to batch. The quantum yields in aqueous solutions (after cap exchange and transfer) are $\sim 50 \%$ of the original values measured for TOP/TOPOcapped QD's in organic solutions. The overall quantum yield of the hydrophilic QD's thus varies anywhere between 10$40 \%$.

QD's cap-exchanged with mixture containing the new DHLA-TEG-biotin ligands were also stable and aggregatefree over extended periods of time (months). Figure 3 shows solutions of QD's capped with a mixture of compound 2 and compound 8 ( $7: 1$ ) in $\mathrm{H}_{2} \mathrm{O}$ of which $\mathrm{pH}$ ranged from 5.5 to 9 . The new water-soluble QD's were stable and well dispersed in the wide $\mathrm{pH}$ range including acidic conditions. This feature is quite different from what we have observed for solutions 


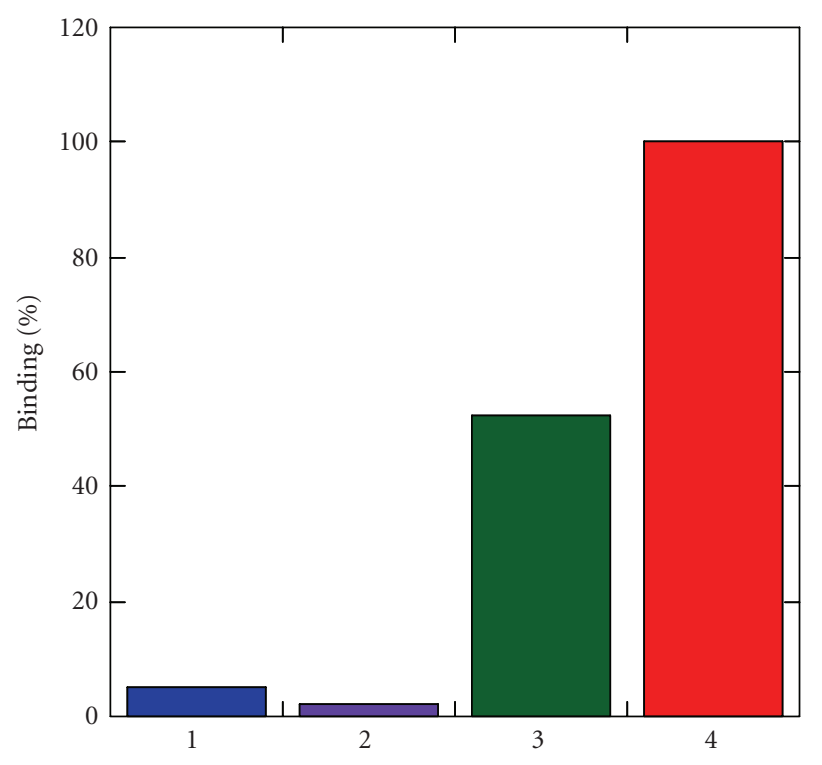

FIGURE 4: Surface binding plate assay of QD's with different surface ligands: (1) DHLA, (2) DHLA-PEG600, (3) DHLA:DHLA-TEGBiotin (at $4: 1$ ratio), and (4) DHLA-PEG600: DHLA-TEG-Biotin (at $4: 1$ ratio). $540 \mathrm{~nm}$ emitting QD's were used.

of QD's capped with either DHLA or mercaptoundecanoic acid (MUA). The DHLA- or MUA-capped QD solutions were well dispersed in aqueous basic media but showed aggregation and eventual precipitation at $\mathrm{pH}$ lower than 7 (data not shown), indicating that deprotonation of carboxyl groups is a crucial factor to solubilize those QD's in aqueous solutions. In contrast, appending a short PEG chain at the end of DHLA molecules extended the stability of QD capped with either $100 \%$ DHLA-PEG600 or a mixture of DHLA-PEG600 and Biotin-functionalized DHLA-TEG to acidic buffer solutions.

Once cap exchange with biotin-terminated DHLA-TEG and transfer into aqueous environment was successfully realized, targeted biological assays were carried out. The binding properties of QD's partially capped with biotin-terminated DHLA-TEG (8) were investigated for their ability to interact with NeutrAvidin-functionalized substrates [24]. NeutrAvidin, which is a deglycosylated form of avidin, was chosen due to its low nonspecific interactions (compared with avidin or streptavidin) while maintaining the strong binding affinity with biotin [24]. Following incubation of the NeutrAvidinfunctionalized substrates with the QD samples, substrates were rinsed 3 times with borate buffer with Tween and the fluorescence signals were collected. Figure 4 shows the fluorescence intensities measured for 4 different QD solutions incubated with NeutrAvidin-coated plates: one capped with DHLA (1), one capped with DHLA-PEG600 (2), one capped with a mixture of $\mathbf{1}$ and DHLA-TEG-Biotin (8) (at $4: 1$ ratio), and one capped with a mixture of 2 and 8 (at $4: 1$ ratio). The data clearly show that only substrates incubated with QD's that were capped with a mixture of biotin-terminated DHLA-TEG produced a large signal-to-background fluorescence signal. In comparison, the substrates incubated with DHLA- or DHLA-PEG600-capped QD's produced only background contribution to the signal. This result indicates that efficient and specific interactions between the biotin groups present on the QD surface and NeutrAvidin on the substrate drive the surface capture of the nanocrystals. It is important to note that the QD's capped with DHLA-TEGbiotin alone were, however, not dispersible in buffer solutions, a result we attribute to the poor water compatibility of biotin by itself and the short TEG. We are exploring the use of longer chain PEG segments for insertion between the dithiol group and biotin. This should make dispersion in buffer solution achievable even at high biotin fractions and promote strong interactions with NeutrAvidin. Those findings will be discussed in future reports.

\section{CONCLUSION}

We have demonstrated simple and efficient synthetic procedures to prepare new biotin-functionalized ligands based on the DHLA motif and employing short TEG segment. The present synthetic route provided high quality and stable compounds, which were further employed to make biotinfunctionalized luminescent QD's, using easy-to-implement cap exchange procedure. The new biotin-appended ligand mixed with either DHLA or DHLA-PEG600 effectively cap exchanged with the native TOP/TOPO and provided QD's that are water-soluble over extended periods of time and biologically active. QD's cap-exchanged with a mixture of DHLA-PEG600 (neutral) and DHLA-TEG-biotin showed specific interactions with NeutrAvidin in surface binding assays. The present synthetic methodologies of hydrophilic surface ligands and cap-exchange reactions promise access to a variety of biological entities. Further studies of these surfacefunctionalized QD's for coupling with a variety of bioreceptors and biological assays are in progress.

\section{ACKNOWLEDGMENTS}

The authors acknowledge NRL, Office of Naval Research (ONR), and the Army Research Office for financial support.

\section{REFERENCES}

[1] M. Bruchez Jr., M. Moronne, P. Gin, S. Weiss, and A. P. Alivisatos, "Semiconductor nanocrystals as fluorescent biological labels," Science, vol. 281, no. 5385, pp. 2013-2016, 1998.

[2] X. Gao, Y. Cui, R. M. Levenson, L. W. K. Chung, and S. Nie, "In vivo cancer targeting and imaging with semiconductor quantum dots," Nature Biotechnology, vol. 22, no. 8, pp. 969-976, 2004.

[3] B. Dubertret, P. Skourides, D. J. Norris, V. Noireaux, A. H. Brivanlou, and A. Libchaber, "In vivo imaging of quantum dots encapsulated in phospholipid micelles," Science, vol. 298, no. 5599, pp. 1759-1762, 2002.

[4] W. C. W. Chan and S. Nie, "Quantum dot bioconjugates for ultrasensitive nonisotopic detection," Science, vol. 281, no. 5385, pp. 2016-2018, 1998.

[5] H. Mattoussi, J. M. Mauro, E. R. Goldman, et al., "Selfassembly of CdSe-ZnS quantum dot bioconjugates using an engineered recombinant protein," Journal of the American Chemical Society, vol. 122, no. 49, pp. 12142-12150, 2000. 
[6] Y. A. Wang, J. J. Li, H. Chen, and X. Peng, "Stabilization of inorganic nanocrystals by organic dendrons," Journal of the American Chemical Society, vol. 124, no. 10, pp. 2293-2298, 2002.

[7] I. L. Medintz, A. R. Clapp, H. Mattoussi, E. R. Goldman, B. R. Fisher, and J. M. Mauro, "Self-assembled nanoscale biosensors based on quantum dot FRET donors," Nature Materials, vol. 2, no. 9, pp. 630-638, 2003.

[8] A. R. Clapp, I. L. Medintz, J. M. Mauro, B. R. Fisher, M. G. Bawendi, and H. Mattoussi, "Fluorescence resonance energy transfer between quantum dot donors and dye-labeled protein acceptors," Journal of the American Chemical Society, vol. 126, no. 1, pp. 301-310, 2004.

[9] A. R. Clapp, I. L. Medintz, and H. Mattoussi, "Förster resonance energy transfer investigations using quantum-dot fluorophores," ChemPhysChem, vol. 7, no. 1, pp. 47-57, 2006.

[10] F. Patolsky, R. Gill, Y. Weizmann, T. Mokari, U. Banin, and I. Wiliner, "Lighting-up the dynamics of telomerization and DNA replication by CdSe-ZnS quantum dots," Journal of the American Chemical Society, vol. 125, no. 46, pp. 13918-13919, 2003.

[11] J. B. Delehanty, I. L. Medintz, T. Pons, F. M. Brunel, P. E. Dawson, and H. Mattoussi, "Self-assembled quantum dot-peptide bioconjugates for selective intracellular delivery," Bioconjugate Chemistry, vol. 17, no. 4, pp. 920-927, 2006.

[12] H. T. Uyeda, I. L. Medintz, J. K. Jaiswal, S. M. Simon, and H. Mattoussi, "Synthesis of compact multidentate ligands to prepare stable hydrophilic quantum dot fluorophores," Journal of the American Chemical Society, vol. 127, no. 11, pp. 3870-3878, 2005.

[13] A. W. Schwabacher, J. W. Lane, M. W. Schiesher, K. M. Leigh, and C. W. Johnson, "Desymmetrization reactions: efficient preparation of unsymmetrically substituted linker molecules," The Journal of Organic Chemistry, vol. 63, no. 5, pp. 17271729, 1998.

[14] S. H. Um, G. S. Lee, Y.-J. Lee, K.-K. Koo, C. Lee, and K. B. Yoon, "Self-assembly of avidin and D-biotin-tethering zeolite microcrystals into fibrous aggregates," Langmuir, vol. 18, no. 11, pp. 4455-4459, 2002.

[15] N. Charvet, P. Reiss, A. Roget, et al., "Biotinylated CdSe/ZnSe nanocrystals for specific fluorescent labeling," Journal of $\mathrm{Ma}$ terials Chemistry, vol. 14, no. 17, pp. 2638-2642, 2004.

[16] D. Tong, J. Yao, H. Li, and S. Han, "Synthesis and characterization of thermo- and $\mathrm{pH}$-sensitive block copolymers bearing a biotin group at the poly(ethylene oxide) chain end," Journal of Applied Polymer Science, vol. 102, no. 4, pp. 3552-3558, 2006.

[17] C. B. Murray, D. J. Norris, and M. G. Bawendi, "Synthesis and characterization of nearly monodisperse CdE (E = S, Se, $\mathrm{Te})$ semiconductor nanocrystallites," Journal of the American Chemical Society, vol. 115, no. 19, pp. 8706-8715, 1993.

[18] M. A. Hines and P. Guyot-Sionnest, "Synthesis and characterization of strongly luminescing ZnS-capped CdSe nanocrystals," Journal of Physical Chemistry, vol. 100, no. 2, pp. 468$471,1996$.

[19] B. O. Dabbousi, J. Rodriguez-Viejo, F. V. Mikulec, et al., "(CdSe $) \mathrm{ZnS}$ core-shell quantum dots: synthesis and characterization of a size series of highly luminescent nanocrystallites," Journal of Physical Chemistry B, vol. 101, no. 46, pp. 94639475, 1997.

[20] Z. A. Peng and X. Peng, "Formation of high-quality CdTe, $\mathrm{CdSe}$, and CdS nanocrystals using $\mathrm{CdO}$ as precursor," Journal of the American Chemical Society, vol. 123, no. 1, pp. 183-184, 2001.
[21] A. R. Clapp, E. R. Goldman, and H. Mattoussi, "Capping of CdSe-ZnS quantum dots with DHLA and subsequent conjugation with proteins," Nature Protocols, vol. 1, no. 3, pp. 12581266, 2006.

[22] I. L. Medintz, L. Berti, T. Pons, et al., "A reactive peptidic linker for self-assembling hybrid quantum dot-DNA bioconjugates," Nano Letters, vol. 7, no. 6, pp. 1741-1748, 2007.

[23] F. Pinaud, D. King, H.-P. Moore, and S. Weiss, "Bioactivation and cell targeting of semiconductor CdSe/ZnS nanocrystals with phytochelatin-related peptides," Journal of the American Chemical Society, vol. 126, no. 19, pp. 6115-6123, 2004.

[24] G. T. Hermanson, Bioconjugate Techniques, Academic Press, San Diego, Calif, USA, 1996. 

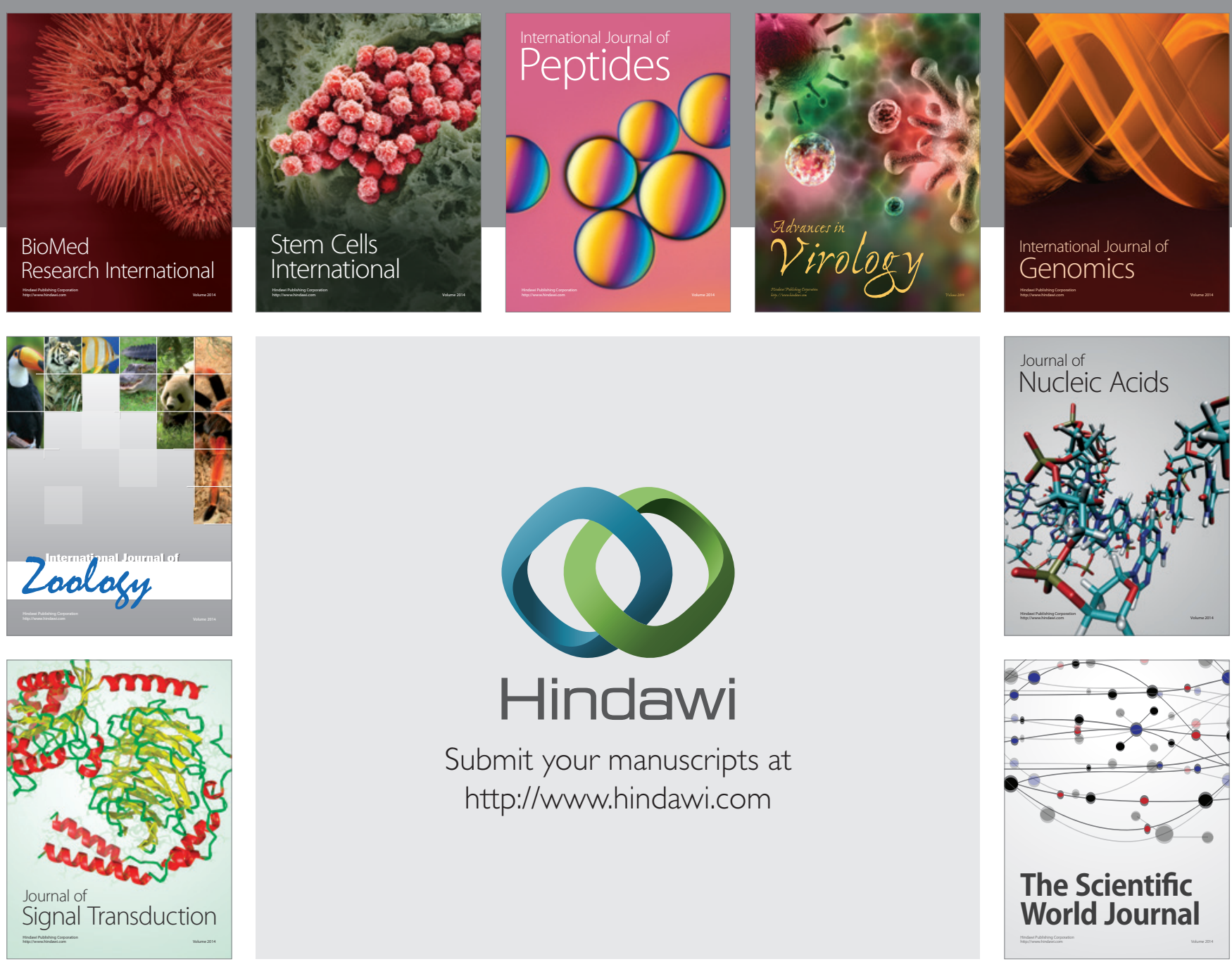

Submit your manuscripts at

http://www.hindawi.com
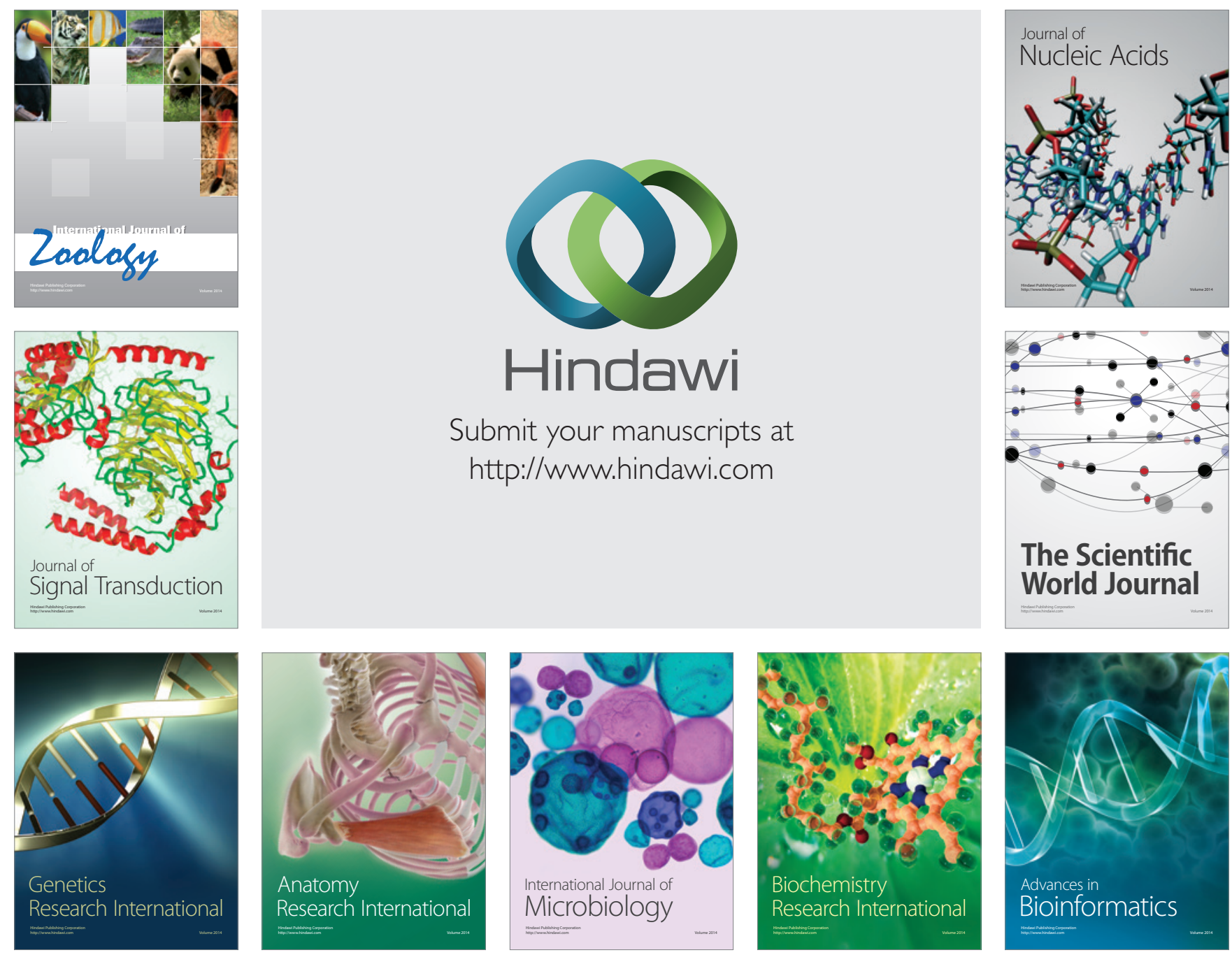

The Scientific World Journal
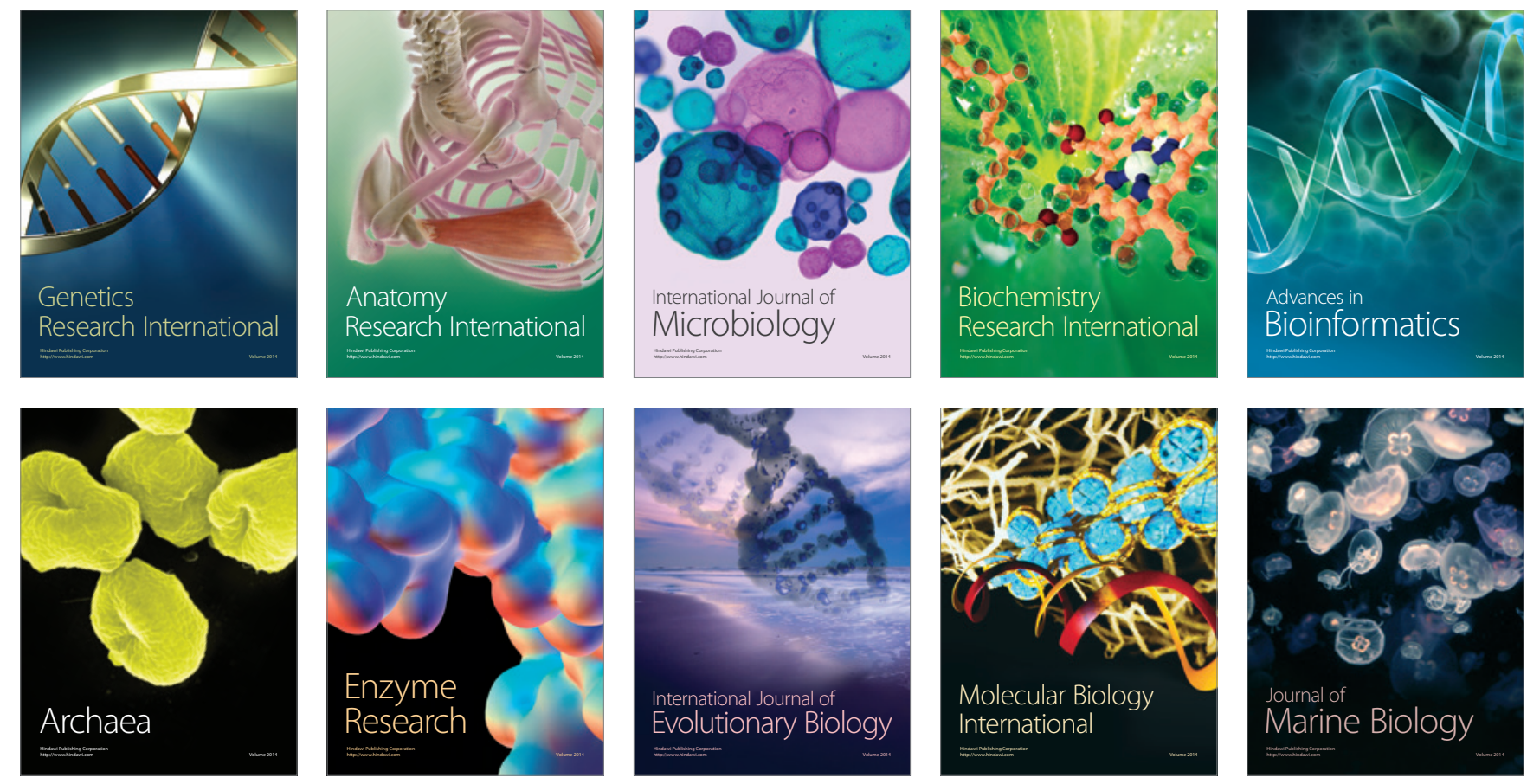